\title{
EL LIBRO-ARTE / LIBRO DE ARTISTA: TIPOLOGÍAS SECUENCIALES, NARRATIVAS Y ESTRUCTURAS
}

\author{
Bibiana Crespo Martín*
}

Facultad de Bellas Artes. Universidad de Barcelona.

\begin{abstract}
Resumen: El propósito de este estudio es indagar a fondo en aquellos aspectos propios y característicos del Libro-Arte / Libro de Artista para que puedan ser considerados como tales y no como otra disciplina artística.

Esta disquisición evidencia una sistematización de las particularidades, análisis de las características y posibilidades de manipulación de la secuencia, el texto y la forma como elementos propios de la esencia del Libro-Arte / Libro de Artista. Así mismo, se establecen las múltiples y diferentes maneras en que puede abordarse el tratamiento de la lectura, el texto y la estructura; constatando la riqueza, versatilidad y maleabilidad que ofrecen y su transcendencia en la individualidad y singularidad de los Libros-Arte / Libros de Artista de cada artista.

Palabras clave: Libro; libro-arte; libro de artista.
\end{abstract}

Title: BOOK-ART / ARTIST'S BOOK: SEQUENTIAL TYPOLOGIES, NARRATIVES AND STRUCTURES.

Abstract: The aim of this study is to thoroughly investigate the typical and characteristic aspects that define Book-Art / Artist's Books as such, and not as any other artistic discipline.

This examination shows a systematization of peculiarities, analysis of specific characteristics and the possibility to manipulate their sequence, text and form, as distinctive elements of the essence of Book-Art / Artist's Book. The investigation also establishes the multiple and different ways of approaching the act of reading, the text itself and the structure of Book-Art / Artist's Book. In addition, it confirms the richness, versatility and malleability that Book-Art / Artist's Book offer and highlights the relevance of the individuality and singularity of Book-Art / Artist's Book made by specific artists.

Keywords: Book; book art; artist’s book.

\section{INTRODUCCIÓN}

El Libro-Arte /Libro de Artista ${ }^{1}$ como soporte de creación cuenta ya con una tradición de más de un siglo y con ello podemos aventurarnos a afirmar que casi no hay artistas contemporáneos de primera magnitud que en un momento u otro no hayan experimentado con esta forma de arte. Gracias a ello, el Libro-Arte ha sido decisivo para el arte contemporáneo.

\footnotetext{
*bbcrespo@ub.edu

Recibido: 26/04/2011; 2ª revisión: 09/11/2011; aceptado: 23/11/2011.
}

CRESPO MARTÍN, B. El libro-arte / libro de artista: tipologías secuenciales, narrativas y estructuras. Anales de Documentación, 2012, vol. 15, nº 1. http://dx.doi.org/10.6018/analesdoc.15.1.125591. 
Pero, para que determinadas obras se enmarquen bajo el concepto de Libro-Arte, más que bajo el concepto de objetos o esculturas que se parecen a libros o con referencias al libro, tienen que mantener alguna conexión con la idea del libro, como es la presentación del material con relación a una secuencia que dé acceso a sus contenidos o ideas. Esta definición entre flexible o imprecisa y amplia o rica en torno a los libros que son un montón de fichas, de piezas sólidas, de material limitado... desafía la caracterización de un Libro-Arte. De la uniforme e intencionada en un extremo, a la no-uniforme y antiintencionada por el otro.

Así pues cabe analizar aquellos aspectos propios y característicos del Libro-Arte para que puedan ser considerados como tales.

La primera clasificación genérica de estas características viene dada por la relación que el Libro-Arte mantiene con la secuencia, el texto y la forma. A la vez, cada uno de estos conceptos puede ser abordado de múltiples y diferentes maneras. El tratamiento de estos tres elementos, gracias a la riqueza y maleabilidad que ofrecen, es lo que dota de individualidad y singularidad a los Libros-Arte de cada artista. La secuencia, el texto, la forma, las imágenes, la fotografía, la página, el todo.

Diversas voces reconocidamente autorizadas en la teorización de los Libros-Arte han abordado el análisis de sus características esenciales desde múltiples ángulos y a ellas nos remitiremos de continuo en este ensayo, pero cabe mencionar aquí que la clasificación y estudio sobre las tipologías secuenciales, narrativas y estructuras que aquí presentamos es fruto de las investigaciones desarrolladas por la autora del presente artículo.

El potencial del libro en términos visuales es complejo y multivalente. Los métodos de producción de elementos visuales en un libro son altamente variados. Todos los materiales plásticos tienen su cabida, junto con la variedad de métodos de impresión. Podemos aseverar que todos los libros son visuales. Incluso los libros que son exclusivamente escritos o de materiales inusuales, o esos que contienen sólo páginas en blanco; todos ellos tienen una presencia y un carácter visual. Todos los libros son táctiles y espaciales, ya que su apariencia física es fundamental para su significado. Los elementos de la materialidad física y visual participan en los efectos temporales de los Libros-Arte. Las cubiertas, el peso de papel, pliegues, todo contribuye en la experiencia de un libro. Sin embargo, está claro que hay libros que maximizan su potencial visual explotando las imágenes, colores, materiales fotográficos, secuencias, yuxtaposición o narratividad.

No obstante, la clasificación de los Libros-Arte va más allá de las páginas, cubiertas, títulos, encuadernación, ilustraciones, tipografía... quizá lo que determina su clasificación y aumenta lo que representa su gran potencial, más que cualquier otra cosa, son las demostraciones de su sensación de lectura. Los Libros-Arte se pueden explorar, leer y percibir de múltiples maneras. Generalmente "solicitan” ser leídos de forma diferente al resto de libros. Permiten al lector explorar más allá de las convenciones lógicas del lenguaje y de la racionalidad de la página impresa en dos dimensiones. Según lo entienden 
Tim Guest y Germano Celant en su obra Books By Artists, la lectura de este tipo de libros envuelve un grado de absorción mental que sólo puede ser comparado con el de la autohipnosis ${ }^{3}$.

Por otra parte, el proceso íntimo de descubrimiento es fundamental para la experiencia del Libro-Arte como forma. Desde sus muchas funciones diarias hasta su existencia metafórica, el libro tiene un potencial que ofrece un espacio privado para la comunicación e intercambio a través de bastos espacios de tiempo y geografía, para entrever o vislumbrar la expresión de experiencias reveladas o comunicadas, a través del espacio y del tiempo.

Y finalmente, la estructura es un componente importantísimo para el éxito del libro, pero el oficio en la producción del libro no es suficiente para constituir la sustancia del Libro-Arte. Un Libro-Arte tiene que ser más que una sólida producción de oficio, o cae en la categoría de una obra bien editada y estampada. Tiene que tener alguna convicción, algún alma, alguna razón de ser, y de ser un libro. Tiene que ser entendido como una forma altamente mutable, siempre bajo la investigación del artista ${ }^{4}$.

\section{LA SECUENCIA}

La secuencia es un concepto estructural del libro fundamental. Podemos definir la secuencia como la temporización que se ha establecido en el libro, determinando el ritmo de "lectura" de una obra. El uso de la secuencia varía en cada libro. El artista establece las claves que conforman la secuencia y entre ellas prevé, la mayoría de las veces, su manipulación y alteración por parte del espectador. Los límites de un libro y sus parámetros finitos en el tiempo, el espacio y los físicos, son tan básicos que sólo dentro de proposiciones de desmaterialización conceptual o espacios electrónicos pueden ser suspendidos. Pero, incluso las secuencias fijas no pueden aplicarse universalmente.

En un libro académico normal, por ejemplo, la lectura del texto es interrumpida, frecuentemente, por la necesidad de referirse a las notas a pie de página, del final del capítulo o del volumen. Sin embargo, en un libro de referencia, como un libro de cocina, un listín telefónico o un diccionario, las secuencias están diseñadas como un sistema de orden más que como un movimiento lineal. La secuencia, por tanto, participa de la distribución de los elementos en un sistema organizado. La manera en la que la secuencia se articula da a cada libro una identidad única. Una secuencia puede moverse muy rápidamente - los "flip books"5 son un extremo de esta característica- o poner muy poca resistencia a detener el momento. En otros casos, el salto de una página a la otra o el paso de una a otra puede ser utilizado para ralentizar el tiempo, mediante recursos técnicos como solapas interiores, pliegues u otros mecanismos en los que se tiende a retener al lector en las páginas más que a moverse a través del libro. Otros libros se sirven de secuencias contradictorias, en la que leer toda su narrativa obliga e implica girar las páginas varias veces de delante a atrás. 
Determinados libros toman la secuencia como principio estructural. Entonces, la secuencia funciona con significado fuera de las estructuras narrativas. Es decir, las relaciones temporales se forjan página a página y este movimiento o yuxtaposición da significado a las imágenes y la secuencia opera como marco dentro del cual cada elemento hace su contribución.

Está claro que la secuencia y la narración están relacionadas, pero no son redundantes como elementos de las estructuras de un libro. El tiempo en un libro puede construirse de componentes visuales, verbales y materiales, además de sus combinaciones. Y las relaciones entre las historias, los espacios literales y conceptuales de un libro; y su estructura finita, son casi infinitamente variables, dependiendo de la visión imaginativa del artista más que de las limitaciones de la forma del libro.

Analizaremos el estudio de la secuencia desglosándola en: Ininterrumpida, Polisemiótica y Externa ${ }^{6}$.

\subsection{Secuencia ininterrumpida}

Un libro puede funcionar como un todo dinámico en un momento o acción unida. Como hemos mencionado anteriormente los "flip books" nos ofrecen este dinamismo, en ellos cada página funciona como un fotograma de una película. La mayoría de "flip books" suelen ser de pequeño formato ya que necesitan hacer uso de la resistencia del papel para que las páginas se muevan rápidamente entre las manos como lo hace Conrad Gleber en su libro Raising Family -Chicago Books, 1976-.

La secuencia ininterrumpida parece obvia cuando hablamos de "flip books", pero no es estrictamente necesario un mecanismo tan activo para que la secuencia fluya ágilmente. La repetición constante de una imagen que no cambia puede tener un efecto curioso en la secuencia, uno quiere releer la imagen, para verla diferente, incluso para verla cambiar, pero el libro se resiste. De esta manera la repetición en esta obra hace que la secuencia o "lectura” sea ágil. Las páginas pueden girarse rápidamente, en busca de una resolución. Pero la resolución no viene, de hecho, está anclada en la propia repetición que parece moverse velozmente hacia el final. Si la imagen no se repitiera, si cambiara, o si aparecieran frases acompañando cada imagen, el efecto sería muy diferente. De esta manera se crea un juego interactivo entre estático y repetitivo, que construye un efecto secuencial muy característico. Así ocurre en la obra de Ida Applebroog But I wasn't there -Dyspepsia Works, 1979-.

\subsection{Secuencia polisemiótica}

Ni todas las narraciones ni todas las secuencias son lineales. La complicación de una forma narrativa puede producirse según el nivel de relación entre texto e imagen dentro de la estructura del libro. Un texto, ostensiblemente sencillo, y su relación con una imagen puede producir multivalencias mediante espacios lineales del texto fracturados por cortes en la continuidad de la narrativa y relaciones texto/imagen que no se duplican unas con otras. De esta manera la secuencia es más que una simple suma de las partes, es una única 
síntesis. A modo de ejemplo cabe mencionar el libro de Roland Penrose The Road is Wider than Long -London Gallery Editions, 1939-.

Las posibilidades de narrativas múltiples o de narrativas que se mezclan y toman diferentes aspectos han hallado expresiones formales altamente complejas en los LibrosArte. Como obra visual y gráfica la utilización del collage, páginas que se despliegan... y multitud de sus partes fragmentadas pueden ser difícilmente reconocibles en un todo unitario. En este tratamiento de la secuencia no hay un camino lineal, no hay una única lectura, y los elementos juegan entre ellos en un montaje continuo produciendo un efecto "polisemiótico" o de múltiples significados tal como nos ofrece Dick Higgins en Of Celebration Of Morning -Printed Editions, 1980-.

\subsection{Secuencia externa}

A menudo los Libros-Arte se fundamentan en una secuencia externa que se convierte en el centro conceptual de la obra. Bajo la noción del libro como un todo hay artistas que configuran sus obras a través de determinantes externos. Muchas veces la base de las obras proviene de determinadas estructuras externas, de otros sistemas, otros alfabetos, números, progresiones matemáticas... Un ejemplo de ello es Every Building on the Sunset Strip -National Excelsior Press, 1962- de Ed Ruscha en el que el referente real de la totalidad de los edificios de esta famosa calle de Hollywood son los parámetros secuenciales que delimitan el libro.

Existen otras secuencias externas como las vicisitudes fisonómicas delatadas fotográficamente sobre las características cambiantes en la cara desde la infancia hasta la madurez, la evidencia de diferentes estilos y modas de llevar el pelo, maquillaje y accesorios. En definitiva el paso del tiempo, a modo de autobiografía fotográfica, y ese aspecto es el que Barbara Schmidt-Heins desarrolla en 1949-1979 -1979-. Por la rígida morfología de esta obra, todo está registrado como información.

O la secuencia externa que fundamenta el libro Brick Wall -Tanglewood Press, 1977de Sol LeWitt (Figura 1). Un libro que muestra un muro fotografiado repetidamente a través de varios momentos del día. Los cambios de luz al principio barren el espacio, luego lo blanquean y más tarde lo retornan a un tono altamente contrastado. Sol LeWitt da un foco enfático a la imagen visual como información. La disposición cronológica es un mecanismo estructural inexorable que determina los momentos en los que el muro fue fotografiado con luces diferentes. Son todas ellas obras que utilizan secuencias externas sin ninguna relación con la narrativa, paginación o secuencia convencional. 


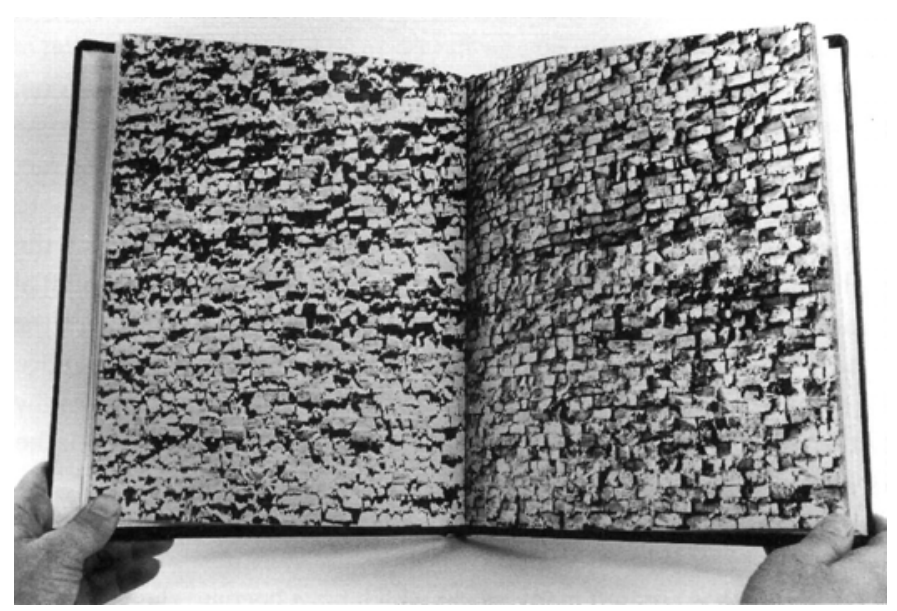

Figura 1. Sol LeWitt, Brick Wall (1977).

\section{EL TEXTO}

La idea del libro como texto nos es familiar desde las novelas hasta las guías de viaje, desde los manuales de instrucciones a los libros de leyes... En los Libros-Arte la apariencia del texto es maleable y está sujeto a la manipulación a través de los significados formales. Como en el caso de las imágenes, los sistemas de producción son muy variados: caligrafía, escritura a mano, plantillas, tampones de goma, tipografía, tipografía por ordenador o fotográfica, etc. Son todo formas posibles de incluir texto en la página. Incluso, a veces, haciendo uso de métodos de reproducción generalmente reservados a las imágenes plásticas, así como valiéndose de lenguajes inventados, y de esta manera el texto está más cercano al campo de las imágenes que al de las letras.

Para establecer un punto de distinción, podemos afirmar que hay Libros-Arte que usan el lenguaje y Libros-Arte que están realmente escritos. No hay una jerarquía moral o estética entre ellos, pero tienen un "sentimiento" diferente respecto al lenguaje. En el primer grupo, el lenguaje tiene una "normalidad", es familiar y consciente; y tiende a ser instrumental y prosaico, más que poético. En el segundo grupo, el lenguaje se precia por sus cualidades materiales y lingüísticas. En estas últimas obras, los aspectos sonoros del lenguaje como el ritmo, los ictus, el cronometraje; y los aspectos visuales como el tamaño, el color, la textura... son tratados como parte de su esencia? .

Según la relación que se establece entre el libro y el texto podemos distinguir las siguientes clasificaciones: Textos Inventados, Poesía Concreta, Poesía Trouvé, Poesía Visual, Libros Preexistentes e Hipertexto ${ }^{8}$. 


\subsection{Textos inventados}

Los textos inventados poseen un alto potencial sugestivo para los artistas. Los signos están imbuidos con significados pero parecen pertenecer a una esfera secreta que cargan estos signos inventados de poder y valor. El lector es atraído por esas formas curiosas con un intenso deseo de descifrarlos, decodificarlos, y darles un contenido elusivo. Pero, no todas las obras que usan textos, idiomas o lenguajes inventados tienen una lealtad o un significado oculto. Humor, parodia y absurdo, a menudo, son componentes de los escritos inventados utilizados como prácticas serias o arcanas.

En el mundo de los Libros-Arte / Libros de Artista hallamos múltiples investigaciones sobre las relaciones entre el libro y la escritura. En ellos la escritura es explorada como un medio gráfico (incluso cosmográfico) ${ }^{9}$. Devienen un verdadero catálogo de las posibilidades de la escritura inventada o no convencional. Es un estudio de las funciones visuales del texto. La lectura se efectúa de arriba a abajo y viceversa, de derecha a izquierda y de izquierda a derecha. En este sentido cabe destacar la colaboración entre Max Ernst e Iliazd en 65 Maximiliana, ou l'exercice illégal -41 Degrees, 1964- (Figura 2) o el exquisito libro lidantYU fAram -1923- de Iliazd.

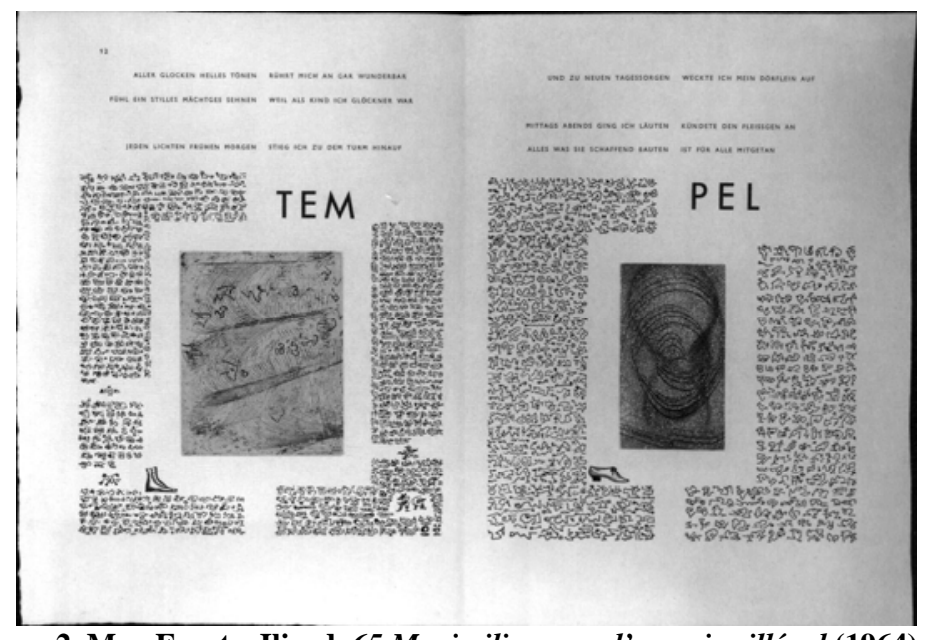

Figura 2. Max Ernst e Iliazd, 65 Maximiliana, ou l'exercice illégal (1964).

La mayoría de las obras del movimiento futurista ruso desarrollaron en todo su esplendor las posibilidades de Zaum ${ }^{10}$. Un lenguaje inventado, cuya principal característica es la sugestión y la inteligibilidad. Un lenguaje transracional —más allá de la razón- que pretendía la unión de los lenguajes convencionales con la expresión de emociones y sensaciones a través de significados poéticos. Sugerente pero incodificable.

Otro modelo de textos inventados lo encontramos en los Letristas, que no sólo estaban relacionados con la invención de una nueva forma de escritura jeroglífica, sino que hicieron de esta actividad el centro de su atención. El rumano Isidore Isou fue fundador y 
líder de este movimiento artístico de los años 50 establecido en París, y estaba convencido que estas innovaciones de los Letristas apuntaban el principio de una tercera fase de la comunicación escrita. Según Isou la historia de la escritura alfabética y la invención de la impresión habían marcado las dos mayores fases del lenguaje escrito. Las aproximaciones de los Letristas iban a inventar la tercera. Isou creía que el Letrismo interrogaba las formas de las letras como unidades fundamentales de comunicación, quería ver destruir y pulverizar el lenguaje y entonces reinventarlo a través de sus experimentos. Nuevas formas y nuevas letras formarían la base de un lenguaje escrito entero y original. Isou demandaba el uso de la "hipergrafía". Pomerand hizo el innovador libro St. Ghetto des Prets en 1950 y Lemaitre creó Roman Hypergraphique en el mismo año. La reinvención del lenguaje como replanteamiento del orden social, político y cultural significaba, en resumen, inventar un nuevo mundo, lo que ya había sido el principio histórico de las primeras vanguardias del siglo XX. En las producciones Letristas abundaban los jeroglíficos, aparecían fotografías, objetos cotidianos, pantallas de cine, todos los materiales asociados con las bellas artes...

Los idiomas y alfabetos inventados proveen gran riqueza formal a la vez que desarrollan gran opacidad conceptual. La firmeza del diseño de las letras de estos textos inventados acentúan su capacidad poética como elemento compositivo dinamizador de sugestiones. El signo gráfico aporta el componente literario narrativo a las imágenes construyendo, muy frecuentemente, un "híbrido" sígnico.

\subsection{Poesía Concreta}

La Poesía Concreta ${ }^{11}$ forma parte de los experimentos vanguardistas de los primeros años de la segunda mitad del siglo XX. Los artistas y autores que trabajaron bajo postulados de Poesía Concreta toman la apariencia visual del lenguaje tanto en su forma como en sus principios estáticos. Mientras los Futuristas y los Dadaístas usaron gran variedad de tipografías y formatos para liberar el lenguaje poético de las constricciones de las convenciones literarias, en particular el sentido lineal del texto, los Poetas Concretos intentaron crear una unidad entre los aspectos visuales y verbales de la obra. El lenguaje y la apariencia de la página de los primeros experimentos de la vanguardia tenían una calidad fortuita y caótica. Como ejemplos, cabe recordar las notas tipográficas de las obras de los Dadaístas Raoul Hausmann y Tristan Tzara. En contraste, la Poesía Concreta tendía a ser condensada e incluso reductora. Las formas de la Poesía Concreta eran variadas, pero unidas por el deseo del sentido literal del significado concretizar —incluir la complejidad verbal en un único material, es decir, la forma visual de la que no puede separarse-. En este sentido, los Poetas Concretos toman el concepto de materialidad más allá del lenguaje que el de los primeros experimentos, tratando de forjar los límites inseparables de significado y presentación a través de la forma visual.

Sin embargo, aunque muchas de las obras de estos poetas estaban coleccionadas en forma de libro, un número considerable de ellas están más relacionadas con la página que con el propio libro. 
Muchas “obras concretas” se caracterizan por la enfatización de la fragmentación del lenguaje y su principal intención es la "eliminación de la sintaxis convencional” y contienen un sinfín de aproximaciones a la construcción del lenguaje a través de reductivos significados visuales. Richard Kostelanetz da buena muestra de todo ello en su ejemplar pieza Visual Language -Assembling Press, 1970-.

Otras obras establecen una relación entre la palabra y la forma del libro a través de sucesivas manipulaciones de las letras que requieren estructurar un texto secundario con sus disecciones. Página tras página revelan las infinitas posibilidades de construcción y reconstrucción como lo hace Emmett Williams en Sweethearts -Somethig Else Press, 1968-.

Mientras que otras obras hacen de la forma del libro tema y vehículo para la exploración del lenguaje. Textos que rompen con la narrativa tradicional del libro para proveer instrucciones de cómo leerlo, haciendo uso de todas las manipulaciones posibles de las letras en las páginas, a través de la línea, del blanco del papel, saturando la página de letras, poniendo una sola frase en medio de la página en blanco... como podemos degustar en Word Rain -Grossman Publishers, 1969- de Madeline Gins.

\subsection{Poesía Trouvé}

La Poesía Trouvé es, sin duda, una de las formas favorita de los escritores contemporáneos y creadores de Libros-Arte. Ambos pretenden recalcar la riqueza, ironía e idiosincrasia del lenguaje. Una de las mayores figuras en la síntesis de la Poesía Trouvé y la forma de libro la encontramos en Bern Porter. Los inicios de las obras de Porter surgen en 1950 con sus publicaciones de Found Poems -última edición por Something Else Press en 1972-. Peter Frank señaló sobre la escritura de Porter: "Porter es al poema lo que Duchamp es al objeto de arte, un desacreditador del fetichismo de la obra de arte y ejemplar del artista como intercesor entre el fenómeno y el receptor" (Frank, 1983, p. 42). Porter utilizó una investigación no-literaria para su obra, aunque, a menudo, su técnica se basa en cortar y pegar fragmentos de lenguaje que se "encuentra” — trouvé-, lo que provoca un impacto tanto visual como semántico. Todos sus libros, desde Found Poems hasta Book of Do's -Dog Ear Press, 1982- o Sweet End -Dog Ear Press, 1989- son un compendio de obras "halladas", seleccionadas de acuerdo con un tema. El talento de Porter reside en su capacidad de manipular la secuencia y el cronometraje de las obras. No están en el libro de manera fortuita, sino que dan a sus páginas una progresión textual y unas relaciones gráficas a través de los matices.

\subsection{Poesía Visual}

Los precedentes para usar la página como espacio o como marco pictórico en el que los elementos verbales toman algunas de las cualidades de la imagen visual se pueden ver en la obra de Filippo Tommaso Marinetti. Artistas y poetas dadaístas y futuristas realizaron numerosos experimentos tipográficos, pero sólo en unas cuantas páginas de sus libros hicieron uso de la página como una imagen pictórica. La práctica de las "palabras en libertad" del futurista italiano Marinetti tomaron la antigua tradición de los modelos de 
la poesía estableciendo una nueva relación con el lenguaje y los poetas vanguardistas. En su publicación Les Mots en Liberté Futuristes (Milán, 1919) Marinetti usó el campo de la página como una estructura para la distribución de elementos verbales de acuerdo con convenciones pictóricas - línea de horizonte y diagramas esquemáticos de relaciones espaciales-. Aprovechándose de ambas estructuras visuales y del valor lingüístico, dobló el potencial de la página, y se convirtió, a la vez, en una imagen y un poema.

A finales de la segunda mitad del siglo XX encontramos algunos Poetas Concretos que usaron la forma visual del lenguaje para investigar las relaciones entre la imaginería verbal y visual muy estrechamente ligado a los caligramas. Sin embargo, existen algunos libros que se dirigen a éste como forma y hacen uso de las páginas como campo. Aunque muchas obras son conscientes de los elementos estructurales de la página, muy pocas de éstas son pictóricas en su organización o referencia.

Queremos puntualizar otra de las acepciones de Poesía Visual. Aquella que habitualmente viene ejemplificada por la figura de nuestro Joan Brossa (1919-1998). Poeta y creador visual, uno de los fundadores del grupo catalán Dau al Set que bebió de las fuentes del Surrealismo. Su gusto por el cultivo de la asociación libre entre las palabras y las cosas le llevó a crear una serie de objetos poéticos en los que conjugaba la ironía con la crítica política. Sus poemas visuales o poemas-objeto responden a pequeñas instalaciones u objetos que crean un discurso poético espacial. Obviamente, no es este tipo de obras en las que se centra nuestro estudio sino aquella a la que Cilve Phillpot se refiere, como forma visual "Por qué tanto escritas como impresas las palabras se alzan para el lenguaje hablado, es fácil no darse cuenta que leer es una actividad visual" (Phillpot, 1985, p.119). Y de esta forma nos lo brinda Keith Smith en Show job book 115 -Smith, 1986-.

\subsection{Libros preexistentes}

Un libro puede ser transformado, o partes de un trabajo pueden ser recortadas y usadas para hacer una nueva obra. Este puede ser un método de trabajo que permite invención e innovación y a la vez el artista se posiciona conscientemente en su implicación como lector ${ }^{12}$. Trabajar con un libro preexistente no significa realizar una réplica de una forma convencional, pero tampoco es completamente un nuevo escenario sin ningún vínculo con el vocabulario de las formas existentes. El libro transformado es una intervención. Generalmente incluye actos de inserción, cortar fragmentos, borrar en la superficie de la página que ya está articulada... Una agresividad, una violación de un texto existente que está relatado en un acto gentil para crear una nueva obra. En una obra transformada la presencia del original puede ser reducida a casi nada, o estar tan fragmentada y reestructurada que llegue a ser irreconocible.

Mencionaremos algunos ejemplos cuyo proyecto se basa en libros y textos preexistentes para extractar la gran oferta de posibilidades que los artistas han desarrollado, como Image and Apearence de Murray -Halifax, 1974- un tratado filosóficocrítico extraído de un libro cuyo título completo era The Image and Apperarence of the 
Human Body by Schilder. El sistema de Murray es sencillo. El texto original aún está presente y aún se puede leer, mientras que el nuevo texto se lee en sentido contrario del original. O como The Final Results of Psicoanalytic Treatment -Pyramind Art Centre, Nueva York, 1991- de Mary Lum, ésta es una nueva versión de la obra de Sigmund Freud. Las intervenciones son muy sutiles: unas cuantas palabras resaltadas, un fragmento del texto alterado por el tono de la impresión... la irregularidad del texto son síntomas neuróticos en los que nunca se encuentra su propia coherencia.

Pero, sin duda, una de las obras paradigmáticas que toma como premisa la transformación conceptual de una obra anterior, es la versión de Marcel Broodthaers de la obra del poeta simbolista francés Stéphane Mallarmé Un Coup de Dés Jamais N’Abolira Le Hasard (1914) (Figura 3). Broodthaers ofrece un análisis conceptual del poema de Mallarmé después de casi un siglo. Broodthaers en su Un Coup de Dés (1969) (Figura 4) tomó la estructura y las propuestas de Mallamé para dicho poema y lo presentó como una obra esquemática ¿Dónde está el significado de esta obra? Broodthaers reduce el poema a su estructura o, en otras palabras, eleva la estructura de la obra a un concepto tan valioso que se convierte en el epicentro de su estudio. La interpretación de la estructura es concreta, visible y casi táctil. Cada verso del poema de Mallarmé está sustituido por una línea negra, simple y geométrica. En la segunda de las tres versiones que realizó sobre este poema, utilizó papel traslúcido porque ello le permitía la suspensión espacial de las frases en las páginas. Bajo este prisma revisionista o apropiacionista sería difícil imaginar un tratamiento más sutil o uno más capaz de demostrar la esencia de la obra de Mallarmé.

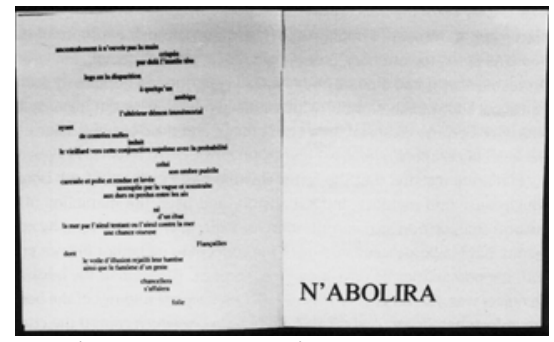

Figura 3. Stéphane Mallarmé, Un Coup de Dés Jamais N’Abolira Le Hassard (1914).

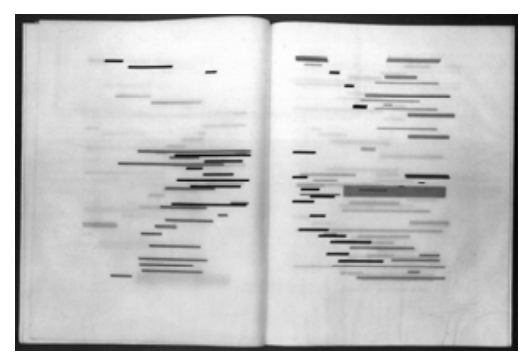

Figura 4. Marcel Broodthaers, Un Coup de Dés (1969). 


\subsection{Hipertexto}

El término hipertexto fue acuñado por Theodor $\mathrm{H}$. Nelson hace más de cuarenta años. Designa una manera de escritura electrónica no secuencial, basada en una estructura arbórea que permite saltar de una unidad textual a otra a partir de unas partículas vinculadas. El grado de desarrollo tecnológico actual permite incorporar textos verbales, imágenes (fijas o en movimiento) y sonidos. El hipertexto se visualiza popularmente como una consecución de textos conectados por vínculos que ofrecen diversas opciones de navegación al lector. Son reversibles, se puede acceder por diversas entradas.

Debido al tratamiento específico que el hipertexto hace del texto es consubstancial a los libros electrónicos ya que son estos los que usan el hipertexto como sistema textual. Una de las formas de manipulaciones electrónicas es el libro como hipertexto. En el formato hipertexto los elementos de la línea del texto son puntos de acceso para otra área de otro texto base. Aunque cada sección individual debe desplegarse de manera lineal, la hilera del texto se enlaza dentro y fuera de cada una en una secuencia mutable. Una historia puede contarse desde múltiples puntos de vista, el lector debe acceder a uno o más de ellos. Algunos programas de hipertextos permiten al lector escribir en el texto, transformando su contenido, tema, estructura... En un sentido estricto, un hipertexto no es narrativo, desde el momento que es un juego posible de enlaces de textos en hilera, más que un solo texto. Al hipertexto puede accederse pasivamente, dejando la historia seguir un curso establecido por el escritor como si se desarrollara en la pantalla, o se activará por la expresión del lector de puntos de preferencia donde el argumento se forja. La actitud ante el hipertexto, cruda aunque posible, puede ser comparada a la de leer un periódico o una revista en el que hay múltiples historias, con difusas instrucciones de continuidad, moviendo al lector a través del desorden de los fragmentos. Inevitablemente uno lee a través de las columnas de lo impreso, más que simplemente seguir una sola historia, este es un montaje primitivo de los elementos de hipertexto. En el hipertexto estos montajes y conexiones están deliberadamente trabajados para hacer del texto entero una telaraña o red, relaciones unidas a través de esta red de trabajo, moviéndote por los hilos de conexión, bifurcaciones o historias.

A causa de su disposición espacial, la lectura de hipertextos se convierte en una "lectura topográfica" de un "planisferio del conocimiento" hipertextual. El problema de orientarse dentro del "mapa (rizomático) de la semiosis" equivale al problema de quien lee un mapa sin conocer su propia ubicación dentro de él. Sin embargo, en el momento en el que la motivación de la lectura en Internet no está orientada pragmáticamente, sino estéticamente, nuestra ubicación dentro de la red pierde relevancia.

Esto parece constituir un elemento fundamental del concepto de la literatura en Internet: el lector tiene la libertad de crear por sí mismo el orden del discurso o de dejarse confundir por el desorden de los fragmentos. Condicionado por la ordenación espacial del texto, el lector puede liberarse de la "obligación de lo lineal", y la "selección comandada por el lector" se convierte, de esta manera, en programa. En lugar de un orden sintáctico - textual prescrito - surge un orden asociativo que únicamente se establece durante y a 
través del acto de leer. De esta manera, el flujo de la lectura se verá interrumpido, en la medida en que el lector haga uso de su libertad de dejarse guiar desde el fragmento textual actual a otro distinto.

El escritor norte-americano Robert Coover habla de una nueva lineabilidad narrativa que depende de la elección del lector en el laberinto hipertextual y admite la introducción de nuevos elementos, nuevas estrategias o nuevos senderos por parte de los lectoescritores, siempre que se preserve el "seguimiento" de la historia y se huya de los anacronismos. Para conseguirlo, Robert Coover sugiere que, a lo mejor, los productores de hipertexto habrán de trabajar dos de los géneros literarios que no se basan en la secuencia causal: las variaciones sobre un tema y las enumeraciones, y se ha de evitar que la desaparición de cualquier elemento no provoque la inteligibilidad de toda la secuencia. Por ello, la elaboración de la ficción hipertextual se basa más en la repetición que en cualquier cadena causal, aunque el lector después asuma una creación de sentido particular basada en la secuencia lineal que compone su lectura. El usuario se convierte en transeúnte de un texto discontinuo que se puede modificar con su lectura.

El artista británico Heath Bunting (1966) elabora muchas de sus creaciones basándose en propuestas hipertextuales. Una muestra de ello es su obra Visitors Guide To London <http://www.irational.org/heath/london> (1994-95) (Figura 5), una guía cibernética de Londres que ofrece recorridos turísticos poco convencionales de su ciudad natal. Determinadas palabras pueden "linkarse" y dan acceso a otros textos e imágenes. El tratamiento del texto, al igual que el de las imágenes, hacen posible mútliples circuitos de lectura. Tanto el texto como las imágenes se expanden a criterio del espectador, y el discurso siempre depende de las elecciones del lector. El "visitante" puede escoger la dirección que desea tomar — Noroeste, Oeste, Suroeste, Este-, las calles por las que quiere pasar, el metro...

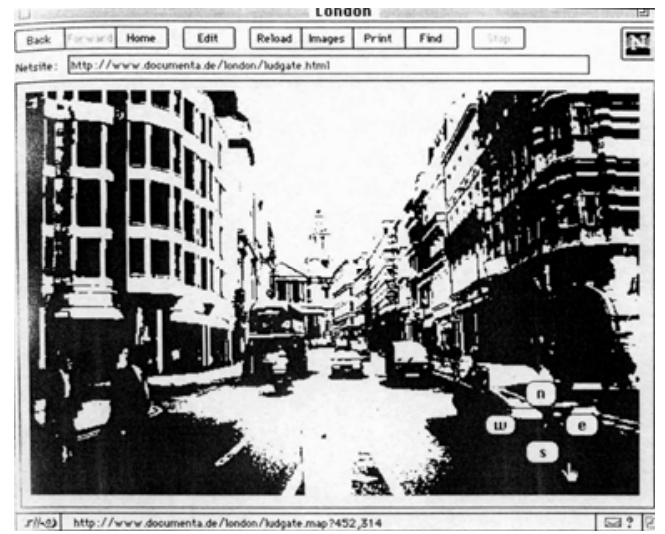

Figura 5. Heath Bunting, Visitors Guide to London- <http://www.irational.org/heath/london> (1994-95). 
La "obra” ahora se realiza exclusivamente en el acto de la lectura. En cada uno de estos actos ésta asume una forma distinta, aunque en su límite esté inscrita en el potencial ofrecido por el algoritmo. Cada lectura es, en cierto sentido, la primera y la última. El texto verbo-audio-visual ya no es la marca de un sujeto (puesto que el sujeto que lo realiza es otro: el lector/usuario) en el cual el sujeto enunciativo sólo suministra el programa, y el sujeto actualizador realiza una parte de su potencial. Incluso se puede decir que la obra combinatoria redefine la distribución de los papeles en la escena de la escritura: los polos autor/lector, productor/receptor se intercambian de forma mucho más operativa. El texto permutable es la propia expresión de esa inversión de papeles, donde el lector recupera su papel fundamental como co-creador, contribuyendo decisivamente a la realización de la obra.

"Todas las direcciones son equivalentes. El espectáculo se transforma en la exploración de un territorio, el viaje por un espacio de datos, (...) Nosotros nos desplazamos en un espacio de ideas, un mundo de pensamientos y de imágenes análogas a las que existe en el cerebro, y no en los proyectos de un urbanista” (Violla, 1989, p.71).

\section{LA FORMA}

En un libro, la forma o estructura y la encuadernación no es lo mismo. Los métodos de encuadernación y sus convenciones engloban: selección de material, uniones o ensamblajes, coordinación de elementos... un todo que "funcione”. La amplitud estética de la encuadernación va desde lo funcional hasta lo decorativo, minimal o excesivo. La estructura de un libro y su encuadernación están íntimamente relacionados, sin embargo, aquí nos centraremos en la forma, no en la mecánica, sino en la estructura del libro como un sistema organizado más que como un oficio de producción.

Sobre estos aspectos han tratado especialmente, las investigaciones de Keith A. Smith, en las que ha conseguido integrar la estructura y la producción conceptualmente. Sus estudios The Structure of the Visual Book, Text in the Book Format, y Non-Adhesive Bindings $^{13}$ son libros de investigación que aportan mucha información respecto al concepto de forma, de cómo hacer libros, encuadernarlos, etc.

No obstante, debemos remarcar que las propiedades del papel, tapas y encuadernación, pueden actuar en contra o a favor del libro. Resulta muy incómodo tener que luchar con un libro cuyas páginas han sido encuadernadas inintencionadamente contra la veta, o cuyas páginas se caen a consecuencia de una encuadernación mal encolada, etc. Aunque el "oficio" no es un criterio absoluto para hacer libros, ignorar sus principios básicos estructurales puede determinar el fracaso de un libro, que de otra manera podría ser exitoso y atractivo. Resulta muy interesante la puntualización de Hubert al respecto en la que añade connotaciones casi dictatoriales al elegir una determinada forma: 
"Al imponernos reacciones específicas táctiles y visuales, los Libros-Arte pueden controlar, espacial e incluso físicamente, cómo sostenerlos y leerlos. Al escoger hojas hechas a mano de diferentes tamaños, colores y texturas, Ania Staritsky descubrió nuevas formas de manipular e instruir a sus lectores” (Hubert, 1999, p.

53).

Examinando la manera en que los artistas contemporáneos han interrogado la estructura del libro, es importante anotar la obvia pero también profunda reflexión que un libro debe ser concebido como un todo. El libro es una entidad para ser considerado en su totalidad, los libros más afortunados son aquellos que tienen en consideración las interrelaciones de los elementos formales y conceptuales, temáticos y materiales. Como en cualquier arte, no hay ninguna fórmula para coordinar las partes del libro. Hay artistas para los que los usos estructurales tienen prioridad. Por ejemplo, el mencionado Keith Smith cree que la filosofía de hacer un libro reside, ante todo, en resolver consideraciones estructurales, de esta manera la organización física y formal del libro se convierte, para él, en una área sustantiva de actividad y crítica. Smith no quiere decir con ello que el contenido del libro sea un elemento puramente incidental al servicio de la forma, pero será definitiva una buena estructura para un buen contenido. Sin embargo, artistas, como Dieter Roth, realizan el libro a través de un proceso en el que forma de producción y contenido son a menudo uno y la misma idea. Muchas de sus obras dependen de las secuencias y las permutaciones de un gesto formal a través de la repetición seriada.

Expondremos ahora la variedad de formas que el Libro-Arte puede abarcar para ponerse al servicio de los propósitos o intenciones conceptuales del $\operatorname{artista}^{14}$.

\subsection{Códex}

El libro es una compleja organización de elementos materiales y conceptuales. Aunque el libro puede tomar muchas otras formas, la más común, versátil y manipulada con más frecuencia es la forma Códex. La forma Códex o Códice es aquella cuyas páginas están encuadernadas a lo largo de uno de sus extremos conformando el lomo como columna vertebral del libro. Esta es la definición que ofrece Keith Smith en su obra Non-Adhesive Binding (Smith, vol.I, 1985, p. 287). Y agrega que muchos encuadernadores no están de acuerdo con esta definición. Smith se refiere, con esta observación, a que la mayoría de encuadernadores consideran un códex o códice los libros manuscritos de cierta antigüedad y de importancia histórica o literaria, o aquellos anteriores a la invención de la imprenta. Nosotros adoptamos la definición de Keith Smith y tomaremos esta acepción de la forma Códex con la intención de distinguir los Libros-Arte encuadernados de esta manera de otros tipos de estructuras, formas y encuadernaciones que veremos seguidamente ${ }^{15}$.

En los Libros-Arte / Libros de Artista han sido utilizados todos los materiales imaginables, desde ropa y metal hasta lana y páginas de vidrio, cortando o troquelando la página, jugando con las diferentes opacidades del material... todo unido, frecuentemente, en forma de códex. Así como todo tipo de materiales para escribir: los tradicionales pigmentos de materiales orgánicos, sprays, leche, sangre... En resumen, no hay reglas ni 
límites en el uso de materiales en los Libros-Arte y la permanencia o longevidad de éste puede ser extremadamente variable ${ }^{16}$.

Aunque el códex es la forma dominante del libro y con buenas razones, ya que proporciona eficiencia y funcionalidad, como discernimos más adelante hay otras formas que han encontrado su camino en el mundo de los Libros-Arte —obras poligonales, cajas, forma acordeón, rollos, estructuras inesperadas...-

El códex da definición a la estructura de muchos de los Libros-Arte. Mientras el códice puede simplemente usarse en todas sus convenciones, conveniencias y eficiencias, hay muchas formas en las que los artistas han expandido su vocabulario a través de la manipulación de sus características. Podemos encontrar muchas estructuras que son una variación de la forma códex, haciendo uso de las convenciones de uniformidad y secuencia intencionada.

\subsection{Rollo}

La forma tipo Rollo se basa en una larga tira de papel que se enrolla sobre sí misma. Esta forma raramente ha sido utilizada por los artistas. Una notable excepción es la renombrada colaboración entre Sonia Delaunay y Blaise Cendrars. La Prose du Transiberien (1913). Ésta alcanza una dimensión de casi 2 metros de altura y muestra un excelente contrapunto entre la plasticidad de los pochoirs de Sonia Delaunay y la poesía radical de Blaise Cendrars. Otro ejemplo destacable es Preview Review (publicado en 1963) del grupo internacional Fluxus. Esta obra incorpora un listado del comité editorial. Una larga y estrecha tira de papel satinado enrollado de forma muy ajustada. El anverso del rollo incluye partituras de eventos y fotografías documentales de la serie de festivales, todas colocadas en orden alfabético y escrupulosamente democrático. El reverso, encabezado por una composición tipográfica de la palabra Fluxus, continúa con una repetición de la oscura, y en cierto modo siniestra, definición de diccionario de dicha palabra, seguida de los detalles de obras disponibles y a la venta a cargo de algunos miembros centrales del grupo.

A pesar del reducido número de artistas que utilizan esta forma, en virtud de este formato se ha de constatar que la lectura de estas obras es como un lento viaje entre líneas, en el que el lector se sumerge en la página sin principio ni final. Este es uno de los aspectos que podemos replicar a la forma códex, a menudo extremadamente dirigida.

\subsection{Punto fijo}

La forma de Punto fijo se basa en la unión de hojas sueltas por un único punto. Esta estructura dota de mucho movimiento y flexibilidad a la lectura de la imagen y del libro en general. La simplicidad de este tipo de encuadernación permite que el material y la forma de las páginas puedan ser muy variados, a gusto y criterio del artista, es decir, se pueden mezclar hojas de papeles de calidades y tonos diferentes, telas, materiales sintéticos, objetos que no sobrepasen un cierto volumen, materias orgánicas —cabellos, 
pieles...-; y pueden adoptar formas diferentes en cada una de las páginas según la intención que se pretenda.

Las obras con forma Punto fijo gozan de una gran elasticidad interna, ya que las hojas se despliegan a modo de baraja de cartas, y de esta manera el espectador puede decidir ocultar o mostrar cuantas imágenes desee, abordando la imagen y la lectura espacial de muy diversas formas. Tal es la concepción de Conrad Gleber en su obra Chicago Skyline Chicago Books, 1977-.

\subsection{Estructura veneciana}

La Estructura veneciana y la estructura con un Punto fijo son las formas tradicionales de los libros de las culturas de Asia y Pacífico. En la Estructura veneciana las hojas están unidas por dos hilos que las atraviesan longitudinalmente. Estirando los extremos de los hilos el libro queda totalmente plegado y cerrado. La virtud de este sistema es que toma la discreta unidad que la página adquiere en la forma Códex y la adecua a un nuevo sintagma. Más que separar espacialmente, las páginas se conectan en relaciones de continuidad, su superficie funciona como parte de una imagen total. En este sentido es similar a la forma Rollo, pero a diferencia de esta última, generalmente, es una forma más manejable. El efecto es de reordenación de determinadas secuencias de una lectura lineal. Mientras en el Códex hay un salto en cada apertura, los libros de Estructura veneciana brindan la posibilidad de someter las páginas individuales en una gran imagen. En estos libros la página funciona como un segmento, estableciendo unas relaciones físicas de contigüidad visual y no sólo como posibilidad de contigüidad temática. Mientras la forma Códex se describe como una continuidad con interrupciones continuadas, valga la redundancia, en la Estructura veneciana se dan unas relaciones físicas similares a las escenas de una película, donde la experiencia visual está en relación con estas rupturas, aunque están enfatizadas o reprimidas bajo la ilusión de una imagen continua. Un excelente libro elaborado con esta estructura es Memory Loss -Visual Studies Workshop, 1988- de Scott McCarney.

\subsection{Acordeón}

La forma Acordeón consiste en el pliegue de una hoja de acá para allá sobre sí misma y alternativamente para crear las páginas. Se trata de una forma muy común en los LibrosArte. Los libros acordeón tienen la ventaja de crear la semblanza de continuidad de la lectura en el espacio y a la vez poderse romper, según el criterio del espectador. Esto permite a la obra tener un movimiento ininterrumpido funcionando simultáneamente como un libro a cuyas páginas y aperturas pueden accederse en cualquier punto de la secuencia. El espacio continuo puede ser utilizado a imitación del espacio de las páginas de la forma Códex o puede sobrepasar esos límites. El acordeón puede ser leído de izquierda a derecha o viceversa, sin linealidad particular. Los elementos gráficos de las hojas dirigen la mirada a través de la obra como si se tratara de un paisaje, interactuando sin las constricciones de las estructuras de la página que generalmente determinan la lectura. 
Sus adaptaciones con las formas anteriormente descritas son muy variadas. Podemos encontrar obras en forma de códex en la que cada página es en realidad un pequeño cuadernillo plegado en forma acordeón, obras con estructura veneciana tratándose de una única hoja de papel, diversos cuadernillos plegados en forma acordeón unidos por un punto fijo, una forma acordeón de la que surjan espacios interiores con hojas cosidas en forma códex, etc. Las posibilidades son infinitas y tan diversas como la inventiva de los $\operatorname{artistas}^{17}$.

La obra de Lucio Fontana Concetto spaziale (1966) (Figura 6) presenta un espectáculo de luces y brillos. Una lámina de cobre doblada en forma acordeón y con algunos círculos troquelados en las "páginas" ofrecen un juego de centelleos y sombras, gracias al relucir del metal pulido, a la luz que se inserta por los pequeños orificios y a la sombra que proyecta la propia iluminación en las páginas contiguas.

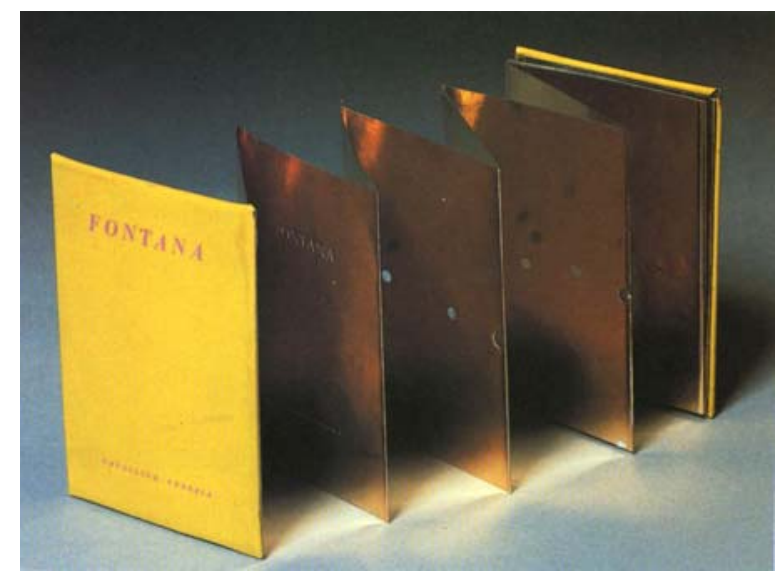

Figura 6. Lucio Fontana, Concetto spaziale (1966).

\subsection{Formas compuestas}

Las cinco formas o estructuras principales de libros —Códex, Rollo, Punto fijo, Estructura veneciana y Acordeón- pueden combinarse entre ellas e incorporar en un mismo formato dos o más tipos de encuadernaciones creando Formas compuestas. Los libros resultados de la combinación de diferentes formas tienen estructuras complejas que, a menudo, ofrecen permutaciones y variaciones en el ritmo de lectura, sin un único orden preestablecido, ya que existen o se proponen varios itinerarios posibles. Estas características invitan tanto al artista como al espectador a jugar con las infinitas posibilidades de la forma del libro. De estas Formas compuestas hay tres tipos que han alcanzado tal popularidad que merecen considerarse como formas singulares y distinguidas. La forma Gemela o "Dos-à-Dos", la forma "French Doors” y la forma Concertina. Es importante reseñar que en los tres casos se trata de otros formatos o estructuras, pero no se trata de nuevas o diferentes encuadernaciones a las explicadas 
anteriormente, ya que como tales formas compuestas se sirven de las encuadernaciones tradicionales para crear nuevas formas.

\subsubsection{Gemela o "Dos-à-Dos"}

Una de las formas compuestas más antigua es la que está constituida por un doble códex. Añadir un códice a otro códice. La forma Gemela o “Dos-à-Dos” emplaza dos textos separados, con dos cosidos separados, aunque muy próximos entre sí, ya que comparten la cubierta trasera. Como están en direcciones opuestas no pueden leerse simultáneamente, porque mientras se lee uno de los códices, la cubierta frontal del segundo códice es temporalmente la cubierta trasera del primero.

Esta forma compuesta fue más común en siglos anteriores para tener dos volúmenes en un único ejemplar, como era el caso del Antiguo y Nuevo Testamento, la Ilíada y la Odisea... Pero, en el terreno de los Libros-Arte esta estructura, además de no ser muy frecuente, no encuentra destacables ejemplos.

\subsection{2 “French Doors”}

La forma "French Doors" al igual que la forma Gemela o “Dos-à-Dos”, está constituida por un doble códex. Los códices están encuadernados por separado y tienen en común la cubierta trasera. Esta cubierta trasera es la suma del ancho de las dos cubiertas traseras de los dos códices, formando una sola, ya que ambos se encuentran en el mismo plano de lectura.

Un volumen tendrá el lomo en el extremo izquierdo y el otro en el extremo derecho. Al disponer de un espacio mucho mayor en el interior del libro, las páginas permiten infinitos juegos compositivos, como por ejemplo: que la lectura de cada volumen sea independiente, que las páginas del volumen izquierdo tengan su continuidad secuencial en el volumen derecho, formas que se completen entre ellas, troquelados en los extremos de las hojas creando nuevas formas de nuevas páginas en el interior, hojas con cortes en diagonal, hojas de diferentes tamaños y materiales, hojas que se solapen, etc. Una estructura que permite visionar simultáneamente dos interpretaciones o dos aspectos de una misma cuestión. Y de esta forma "French Doors" se sirve Ann Chamberlain en su obra de 1991 Family Album / Album Familiar en la que en el códex de la derecha presenta los componentes paternos de su identidad y en el códex izquierdo la influencia materna, la visión conjunta de ambas partes es lo que conforma la totalidad de su personalidad.

\subsubsection{Concertina}

De las Formas compuestas la Concertina es una de las formas más usada por los artistas. Diferentes secciones están cosidas a una encuadernación cuyo lomo es un pliego acordeón. Cada sección es un cuadernillo que está cosido a los pliegos de una forma acordeón, indistintamente en su parte interior o exterior, o incluso combinándolo, y el lomo puede estar fijo o aprovechar la movilidad del pliegue acordeón dejándolo suelto. 
La forma Concertina permite a las páginas fijas de la forma Códex extender su espacio. Las páginas están separadas unas de otras por un plegado en el lomo a las que están cosidas, así pues se le da más atención a su autonomía como páginas. Su disposición permite, igual que en la forma Códex, páginas troqueladas y otras subdivisiones u órdenes interiores. Abundan muchas variaciones en la forma y estructura Concertina, ésta ofrece muchas posibilidades compositivas en las tapas y en el lomo, con tiras de papel entrecruzadas, pestañas que crean alternancias cromáticas...

Charles Alexander de Chak Press usó la encuadernación concertina para un libro resultado de la colaboración entre dos poetas, Kit Robison y Lyn Benjinian, Individuals (1988), un diálogo en el que cada “página” es en su esencia dos páginas, la franja superior y la inferior, en las que el texto de los poetas está impreso. La articulación del diálogo se produce en el intercambio de espacios, además de remarcas lingüísticas a través de las secuencias del libro.

\subsection{Cajas}

Otras obras que van más allá de la forma Códex, Rollo, Punto fijo, etc. y, por supuesto, más allá del concepto de encuadernación, son las que toman la forma de caja u otra clase de poliedro. Algunos de ellos resultan ser contenedores de material como si de archivos se tratara. Otros, sin embargo, adoptan la forma caja como estructura imprescindible para el desarrollo de su discurso estético.

La tipología de Libro-Objeto Colección adopta muy frecuentemente la morfología de Libro-Caja en la que se insertan imágenes y/u objetos. Esto suministra al espectador una satisfacción de voyeur que le permite replicar sobre papeles o documentos privados de alguien. Es un acto que se debate entre una violación y una curiosidad necrofílica. Estas obras, a menudo, tienen una calidad nostálgica, son como fragmentos de restos del pasado. Maison Manquante -La Hune Librarie, 1990- (Figura 7) de Christian Boltanski es un magnífico libro fruto de la recopilación de un sinfín de objetos, materiales y diversa documentación relativa a un espacio que en 1945 halló en Berlín y que había sido bombardeado durante la II Guerra Mundial. 

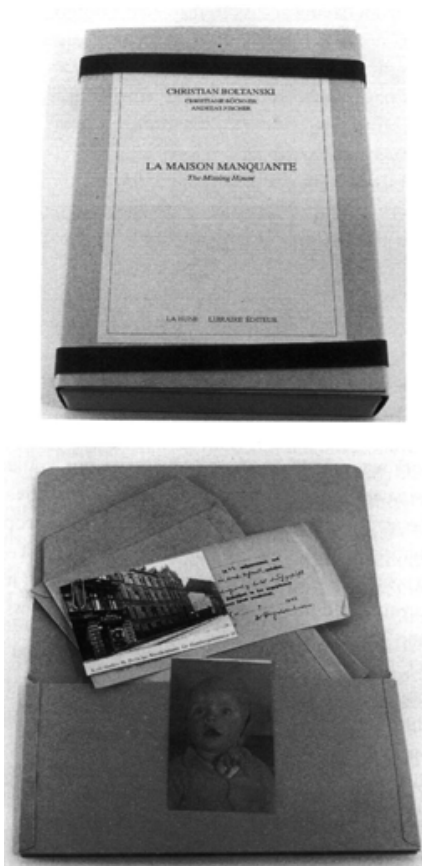

Figura 7. Christian Boltanski, Maison Manquante (1990).

\subsection{Electrónicos}

Finalmente, ya que estamos considerando las múltiples estructuras que los libros pueden adoptar, debemos detenernos en los espacios electrónicos.

El libro como depósito de información o como archivo ha encontrado una vía que responde a las características convencionales de este tipo de libros. El concepto de archivo se adapta plenamente al medio electrónico porque el almacén digital puede contener cantidades ingentes de información e incluso ofrecer simulacros de documentos en la pantalla. La noción de archivo, al estar muy estructurada, es por un lado hierática y por el otro diagramática y accesible. Como un buen sistema de repostar, el archivo parece tener un orden para esto, y si uno imagina y elabora un diagrama en forma de árbol en el que una lógica de categorías y subcategorías se sigue con precisión y cuidado, entonces el archivo ofrece un significado organizado debido a la información que contiene. Pero un archivo no necesita ser meramente una enciclopedia o un tratado de conocimientos, puede ser tan rico como un inventario de información personal o una base de datos de las películas de espías, un mirón al acecho, etc. o una obra de arte, como realiza Antoni Muntadas en su obra File Room (1994) en la que conjuga las cualidades del archivo electrónico con su discurso estético. 
Si bien es cierto que algunas convenciones de la forma Códex —organizaciones inamovibles u organizaciones de información- encuentran su equivalente simulacral en el Libro-Electrónico —como son los e-Book, i-Pad, SoftBook...- - también es evidente que hay nuevos paradigmas y parámetros para las estructuras, los órdenes y la experimentación de los libros, debido a que la tecnología facilita nuevos patrones de pensamiento y creatividad.

El Libro-Electrónico aporta una nueva noción, la del libro como campo, una matriz flotante de información no unida por diagramas jerárquicos o por los hilos de una historia. Entonces el "lector" hojea mediante un movimiento a través del campo como si buceara. Tal proceso tiene poco que ver con los patrones convencionales de lectura o narrativa, $\mathrm{y}$ por lo tanto, funciona a través de un montaje libre. A pesar de certificar que existen Libros-Electrónicos, esta última particularidad —el montaje libre- hace cuestionar en muchos casos que ciertas obras podamos incluirlas en el campo de los Libros-Arte, en lugar de englobarlas dentro del genérico Arte Electrónico. Aunque es cierto que las creaciones electrónicas son el paradigma del arte de final del pasado siglo, ello representa la aceptación del arte de la hibridación y la mixtura de diferentes disciplinas como uno de los principios estéticos elementales de nuestra contemporaneidad.

\section{CONSIDERACIONES FINALES}

Así pues, hemos profundizado en el especial tratamiento que los Libros-Arte conceden a la secuencia, el texto y la forma como sus características principales. Hemos analizado los diferentes tipos de secuencias, las diversas maneras en que puede ser tratado el texto (en el sentido más amplio del término) y la multitud de posibles formas y estructuras que ofrecen los Libros-Arte. La infinidad de recursos que brindan estos tres elementos, queda demostrado que constituyen un valor fundamental para dilucidar la manera en que los artistas han interpelado este asombroso soporte, y el ilimitado juego que ofrecen sólo es comparable a las ilimitadas capacidades imaginativas y creativas de los artistas.

Concluiremos señalando que analizar y delimitar la diversidad de tipologías secuenciales, narrativas y estructuras que el Libro-Arte / Libro de Artista puede adoptar, tal vez contribuye a la construcción de una síntesis para una posible sistematización de estas obras, pese a que por las características de las mismas, la inspiración y creatividad artística rebasa ampliamente cualquier marco en el que se las intente inscribir, y también aquí radica precisamente la grandeza del Libro-Arte / Libro de Artista como creación.

\section{NOTAS}

1 Sobre aspectos relacionados con la taxonomía terminológica-conceptual que conlleva el Libro-Arte ver CRESPO MARTÍN, B. Clasificación y análisis de la terminología desarrollada alrededor del Libro-Arte. Arte, Individuo y Sociedad, 2010, vol. 22, no 1, p. 9-26; y LAUF, C. y PHILLPOT, C. Artists / Author. Contemporary Artists’ Books. Nueva York: American Federation of Arts, 1998. 
2 Destacados estudios en torno al desarrollo y evolución histórica del Libro-Arte son: CASTELMAN, R. A Century of Artists Books. Nueva York: The Museum of Modern Art, 1994; CHAPON, F. Le peintre et le livre:L'Age d'or du livre illustré en France, 1870-1970. París: Flammarion, 1987; CRESPO MARTÍN, B. El Libro-Arte. Concepto y proceso de una creación contemporánea. Saarbrücken: VDM. Verlag Dr. Müller, 2009; HARTHAN, J. The History of Illustrated Book. The Western Tradition. Londres: Thames and Hudson, 1981 y MOEGLIN-DELACROIX, A. Esthétique du livre d'artiste. París: Ed. Jean-Michel Place / Bibliothèque Nationale de France, 1997.

${ }^{3}$ GUEST, T. y CELANT, G. Books By Artists. Toronto: Art Metropole, 1981.

${ }^{4}$ Puesto que no tratamos de hacer un análisis estético-plástico de las obras que citamos hemos convenido referenciar algunos Libros-Arte / Libros de Artista que ejemplifican los aspectos que abordamos sin detenernos en profundidad en su exploración desde otros ángulos igualmente interesantes.

${ }^{5}$ Nos ha resultado inevitable utilizar la nomenclatura anglosajona ya que no hemos encontrado una traducción apropiada para este tipo de libros.

${ }^{6}$ Johana DRUCKER en su obra The Century of Artists' Books. Nueva York: Granary Books, 1995, nos ofrece otra perspectiva analítica sobre el libro como secuencia. En su capítulo del citado libro The Book as Sequence: Narrative and Non-Narrative p. 257-258, la autora desgrana la secuencia desde la dependencia de las convenciones, la foto-narratividad con texto, las narrativas complejas o "polisemióticas", las narrativas documentales, las secuencias visuales no narrativas y aquellas que son "casi" (almost) o "no del todo" (notquite) narraciones.

${ }^{7}$ Sobre el equilibrio que se da en los Libros-Arte entre los aspectos textuales y los visuales ver HUBERT, R. R. Narrative and verbal manipulation. The Cutting Edge of Reading: Artists' Books. Nueva York: Granary Books, 1999, p. 179-206.

${ }^{8}$ En relación a las posibilidades de uso y manipulación del tratamiento del texto ver el capítulo Book as Verbal Exploration en DRUCKER, op. cit., p. 227-256. Y más someramente, CARRION, U. El arte nuevo de hacer libros. HELLION, M. (ed.). Libros de Artista. Nueva York: Turner, 2003, p. 310-323.

${ }^{9}$ Así lo estudia HUBERT, op. cit., en su capítulo Visual deviants and typographical departures, p. 33-51.

${ }^{10}$ Un destacado estudio sobre los Libros-Arte de este movimiento es COMPTON, S. P. Russian Avant-Garde Books, 1917-34. Londres: The British Library, 1992.

${ }^{11}$ Otra manera de abordar los límites indisociables entre la Poesía Concreta, la Poesía Trouvé y la Poesía Visual, y los Libros-Arte es la que argumenta MOEGLIN-DELACROIX en su capítulo de libro Poètes ou artistes?, op. cit., p. 61-98.

${ }^{12}$ HUBERT, op. cit., en el capítulo 5 titulado Altering Books - The Cutting Edge of Reading, p. 71-96 aporta una selección de obras de artistas que han trabajado el Libro-Arte bajo estos postulados de lectores con actitud artística proactiva.

${ }^{13}$ SMITH, K. A. Structure of the Visual Book. Rochester, Nueva York: Visual Studies Workshop Press, (3 $3^{\text {a ed., }}$ 1994) 1984. SMITH, K. A. Text in the Book Format. Nueva York: The Sigma Foundation, (2a ed. 1995) 1989. SMITH, K. A. Non-Adhesive Binding. Vol. I, II y III. Rochester, Nueva York: Keith A. Smith ed., ( $3^{\mathrm{a}}$ ed., 1995) 1995.

${ }^{14}$ Si bien no es nuestro objetivo mostrar los diferentes tipos de encuadernaciones, resulta ineludible la conexión que algunas de las secciones que exponemos tienen con los tipos de encuadernaciones existentes sin que ello comporte en absoluto una clasificación determinada por los tipos de encuadernaciones.

${ }^{15}$ Con el fin de desterrar el error al que puede inducir denominar "códice” a unta tipología de forma - ya que, como se especifica en el texto, esta nomenclatura se refiere a los manuscritos antiguos y especialmente a aquellos anteriores a la invención de la imprenta en 1455- hemos optado por su acepción en latín — códexpara designar a los libros cuyas páginas separadas están unidas en uno de sus extremos. Este tipo de encuadernación se llama "encuadernación rústica" o "pliegos cosidos” pero debido a que esta clasificación de las tipologías estructurales del Libro-arte no responde a una clasificación atendiendo a los sistemas de encuadernación no consideramos apropiado el reduccionismo conceptual que ello conllevaría.

${ }^{16}$ Ver DRUCKER, op. cit., The Codex and its Variations, p. 121-159.

17 A este respecto recomendamos el capítulo 6 Variations on the Accordion, HUBERT, op. cit., p. 97-122. 


\section{BIBLIOGRAFÍA}

BURY, S. Artists’ Books. The Book as a work of art, 1963-1995. Hants: Scolar Press, 1995.

CARRIÓN, U. Bookworks Revisited. The Print Collector's Newsletter, 1980, vol. 11, nº 1, p. 8.

CARRIÓN, U. Definitions. Art-Rite, Invierno 1976-1977, nº 14, p. 6.

CARRION, U. El arte nuevo de hacer libros. HELLION, M. (ed.). Libros de Artista. Nueva York: Turner, 2003, p. 310-323.

CARRIÓN, U. Other Books and So. Bremen: Neves Museum Weserburg, 1992.

CASTELMAN, R. A Century of Artists Books. Nueva York: The Museum of Modern Art, 1994.

CHAPON, F. Le peintre et le livre: L’Age d'or du livre illustré en France, 1870-1970. París: Flammarion, 1987.

COHEN, A. y BLOCH, S.R. The Book Stripped Bare: A Survey of Books by $20^{\text {th }}$ Century Artists and Writters. Hempstead, Nueva York: Emily Lowe Gallery, Hofstra University, 1973.

COMPTON, S.P. Russian Avant-Garde Books, 1917-34. Londres: The British Library, 1992.

CORON, A. Le Livre et l'artiste. Tendance du livre illustré français. 1967-1976. París: Bibliothèque Nationale, 1977.

CRESPO MARTÍN, B. El Libro-Arte. Concepto y proceso de una creación contemporánea. Saarbrücken, VDM. Verlag Dr. Müller, 2009.

CRESPO MARTÍN, B. Clasificación y análisis de la terminología desarrollada alrededor del Libro-Arte. Arte, Individuo y Sociedad, 2010, vol. 22, no 1, p. 9-26.

DRUCKER, J. The Century of Artists’ Books. Nueva York: Granary Books, 1995.

FORD, S. Artists' Books in UK\&Eire Libraries. Art libraries Journal, 1993, vol. 18, n¹, p. $14-25$.

FRANK, P. An Annotated Bibliography. Nueva York: Something Else Press, McPhersonard Company, 1983, p. 42.

GUEST, T. y CELANT, G. Books By Artists. Toronto: Art Metropole, 1981.

HARTHAN, J. The History of Illustrated Book. The Western Tradition. Londres: Thames and Hudson, 1981.

HOFFBERG, J. y HUGO, J. Artwork bookworks. Los Angeles: The Los Angeles Institute of Contemporary Art, 1978.

HUBERT, R.R. The Cutting Edge of Reading: Artists' Books. Nueva York: Granary Books, 1999.

KLIMA, S. Artists Books. A Critical Survey of literature. Nueva York: Granary Books, 1998.

LAUF, C. y PHILLPOT, C. Artists / Author. Contemporary Artists’ Books. Nueva York: American Federation of Arts, 1998.

LIPPARD, L.R. The artists’ Book Goes Public. Art in America, 1977, vol. 65, $\mathrm{n}^{\circ}$ 1, p. 40 41. 
MOEGLIN-DELACROIX, A. Esthétique du livre d'artiste. París: Ed. Jean-Michel Place / Bibliothèque Nationale de France, 1997.

PHILLPOT, C. Artists’ Books From the traditional to the Avant Garde. New Brunswick, New Jersey: Rutgers University, 1982.

PHILLPOT, C. Some Contemporary Artists and Their Books. LIONS, J. (ed.). Artists’ Books: A Critical Anthology and Sourcebook. Rochester, Nueva York: Visual Studies Workshop Press, 1985, p. 119.

ROTHENBERG, J. y GUSS, D. The Book, Spiritual Instrument. Nueva York: Granary Books, 1996.

SMITH, K.A. Structure of the Visual Book. Rochester, Nueva York: Visual Studies Workshop Press, (3ª ed., 1994) 1984.

SMITH, K.A. Text in the Book Format. Nueva York: The Sigma Foundation, (2 ${ }^{\mathrm{a}}$ ed. 1995) 1989.

SMITH, K.A. Non-Adhesive Binding. Vol. I, II y III. Rochester, Nueva York: Keith A. Smith ed., (3 ed., 1995) 1995, p. 287.

VIOLLA, B. Y aura-t-il copropieté dans l'espace des donnés. Comunications, 1989, $\mathrm{n}^{\circ}$ 415, p. 71.

VOGLER, T. Books as Art. Portland, OR: Comus Gallery, 1994. 